\title{
From fans to buyers: antecedents of sponsor's products purchase intention
}

\author{
Alfredo Silva \\ Sport Science School of Rio Maior, Polytechnic Institute of Santarém, \\ Portugal and Department of Sport Management, Life Quality Research Center (CIEQV), \\ Santarém, Portugal, and \\ José Manuel Cristóvão Veríssimo \\ ISEG - Lisbon School of Economics and Management, Universidade de Lisboa, \\ Lisboa, Portugal
}

Sponsor's products purchase intention

\begin{abstract}
Purpose - This study aims to explore the indirect and direct effect of perceived congruence between fans' identification with a team and the intention to buy sponsor's products. The level of perceived congruence between the sponsor and the sports team, as well as fans' attitude toward the sponsor and their purchase intention toward products from the sponsoring company are analyzed.

Design/methodology/approach - A sample of 2,647 football fans who support two well-known Portuguese professional football teams completed a questionnaire. Structural equation modeling with multigroup analysis was carried out to test the model and the hypotheses.

Findings - Team identification has an effect on perceived congruence, on attitude toward sponsors and on intention to buy. The results also show the positive direct and indirect effects of both perceived congruence on attitude toward the sponsoring company and on purchase intention of sponsors' products. However, neither congruence nor attitude show significant results on purchase intention.

Originality/value - This study departs from previous studies, in that it investigates the direct and indirect (i.e. mediated) effects of perceived congruence. Firstly, it analyzes the mediating effect of perceived congruence between team identification and purchase intentions. Secondly, it explores the mediating effect of perceived congruence between team identification and attitude toward the sponsor.
\end{abstract}

Keywords Purchase intention, Team identification, Congruence, Sponsorship, Football fans

Paper type Research paper

\section{Executive summary}

A fan's level of identification with the sports team they support has been widely used as key determinant on sponsorship. However, the evaluation of the direct effects and mediation function of perceived congruence between the sponsor and the sponsored (i.e. supportive team) calls for further clarification (Johnston and Paulsen, 2011). In addition, the abundance of contradictory results (Alonso Dos Santos and Calabuig, 2018; Mazodier and Merunka, 2012; Wang et al., 2011; Zaharia et al., 2016) reinforces the need of fully understanding the importance of perceived congruence on purchase intention. Based on the social identity theory (Tajfel and Turner, 1979), the congruence theory (Osgood and Tunnenbaum, 1955) and the attitude theory (Fishbein and Ajzen, 1975), the current study aims to fill the following critical gaps in the sponsorship literature: to demonstrate the indirect effect of congruence between team identification and purchase intention, to expose the causality between team identification and perceived congruence and to clarify the effect of congruence on attitude toward the sponsor and on the purchase intention toward the sponsor's products. In total, 2,647 fans from two of the most popular football teams in

Funding: Portuguese Foundation for Science and Technology, I.P., Grant/Award Number UIDP/04748/ 2020
Received 16 March 2019 Revised 11 September 2019 Accepted 13 October 2019

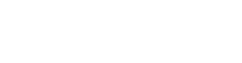

